\title{
De-Agglomeration Kinetics of Feedstocks with Granule Tetragonal Zirconia Polycrystalline Powder
}

\author{
Rong-Yuan Wu and Wen-Cheng J. Wei ${ }^{\star \dagger}$ \\ Institute of Materials Science and Engineering, National Taiwan University, Taipei, 106 Taiwan
}

\begin{abstract}
This study establishes the relationship between homogeneity of tetragonal zirconia polycrystalline (TZP) feedstocks and the kneading time in order to understand the kneading energy adsorption during the de-agglomeration period of pre-existing ceramic granules. Two spray-dried Y-TZP powders with different compress strengths were investigated using torque rheometer and transmission optical microscopy. Several properties, kneading torque $(T)$, Casson viscosity $(\mu)$, Reynolds number $(R e)$, and dispersive index $\left(D_{\mathrm{s}}\right)$ of the feedstocks were introduced, and monitored as a function of kneading time. Optimal processing windows were identified from the dependence of dispersive index with a power number $\left(N_{\mathrm{p}}\right)$. The best shear-kneading procedure was proposed in consideration of best feedstock homogeneity and shortest kneading time. One homogenous feedstock and two comparable cases were prepared for subsequent injection molding, debinding, sintering, and mechanical testing. The fracture strength of sintering parts by a partially homogeneous feedstock can be improved from 520 to 680 MPa by a homogeneous feedstock.
\end{abstract}

\section{Introduction}

$\mathrm{M}$ IXING of various ingredients is very important step in ceramic powder processing. In order to achieve better homogeneity, the volume of binders interchange with the powders used in precision ceramic injection molding (CIM) has gained lots of research efforts in the past decades. ${ }^{1,2}$ The resulted powder/binder packing conditions greatly affect the properties of ceramic parts after sintering. The agglomeration of ultra-fine ceramic powder, one of the processing defects, may result from the inter-particle attractive force and profoundly influence the mechanical properties of the sintered parts.

Ceramic granules may also be fabricated by spray-drying technique. Spherical granules improved the flowing ability needed in storage and die-pressing. However, the granule powder was seldom kept in the powder batch, rather dispersed to discrete particles in ceramic processing. If the kneading (shear) stress is less than the critical powder strength, the powder agglomerate of the granules is held in the feedstock. The agglomerate will be still held until sintering. The defects of agglomerate strongly reduce the fracture strength of ceramic parts.

Yttria-stabilized tetragonal zirconia polycrystallines (Y-TZP) ceramic had a microstructure of a fine grain size. The dense parts of Y-TZP exhibited excellent mechanical properties as well as wear resistance. ${ }^{3}$ However, the Y-TZP powder of high specific surface area rendered the dispersion procedure very difficult. Trunec et al. ${ }^{4}$ compared the results of fine powder batches with and without treatments. The viscosity of a feedstock with powder treatment was lower than other treatments. However,

L. C. Klein-contributing editor

Manuscript No. 10930. Received March 22, 2004; approved November 29, 2004 The authors would like to thank the funding awarded by The Ministry of Education, Taiwan, in the support of The Excellent Center of Nano-Technology at NTU (92BA0041). ${ }^{*}$ Member, American Ceramic Society.

†uthor to whom correspondence should be addressed. e-mail: wjwei@ntu.edu.tw the fracture strength of the sintered parts with the treatment had a greater standard variation than others. Besides, $\mathrm{Wu}$ and $\mathrm{Wei}^{5}$ reported that different kneading sequences could strongly influence the fracture strength of $\mathrm{Al}_{2} \mathrm{O}_{3}$ feedstocks. Similar results showed appropriate powder treatment during the kneading of ceramic feedstocks was important for preventing the degradation and improving the homogeneity of the feedstock. ${ }^{4-6}$

Kneading technology is widely used in industries such as ceramics, catalyst manufacturing, and food processing. The purpose of kneading is to achieve uniform mixing and leads to the mixtures of a good and uniform quality in a short time. There are two primary mechanisms of kneading to achieve uniform mixture, either distributive mixing or dispersive mixing. ${ }^{7}$ Song and Evans ${ }^{8}$ showed that insufficient shear stress provided by the kneader would leave powder agglomerate held in the feedstock even after sintering. The residual powder agglomerates might be active as a fracture origin, must be less than the allowed size based on fracture strength consideration. ${ }^{9}$

In our previous study, ${ }^{10}$ quantitative analysis was done to show the state of feedstock homogeneity. The kneader power applied to feedstock was calculated by power consumption diagram. The result showed that the feedstock homogeneity kneaded under the condition, $150^{\circ} \mathrm{C} / 30 \mathrm{rpm}$ for $60 \mathrm{~min}$, appeared a good homogeneity (dispersive index, $D_{\mathrm{s}}=0.93$ ). Literatures have little research in studying the relationship of powder properties and kneading parameters, such as kneading shear stress, to the feedstock homogeneity, and sintering properties. The objectives of the present work are to evaluate the effects of kneading on the agglomeration and other properties of $3 \mathrm{Y}-\mathrm{TZP}$ feedstock under various kneading conditions. Using the data of homogeneity-kneading time, the full homogeneity of feedstock can be reached and significantly improve the properties of $3 \mathrm{Y}$ TZP ceramics produced by injection molding (IM).

\section{Analysis of Homogeneity and Kneading of Feedstock}

\section{(1) Quantitative Microstructural Analysis of Feedstocks}

The dispersive index $\left(D_{\mathrm{s}}\right)$ is defined as the volumetric fraction of the powder in agglomeration state that appears on the feedstock microstructure. The definition of dispersive index can be found in the literature. ${ }^{11}$ The symbol $\phi_{\mathrm{a}}\left(1-D_{\mathrm{s}}\right)$ means that the fraction of the particles remains in the form of agglomeration. The quantitative method has been presented in the previous literature. ${ }^{10}$

\section{(2) Power Consumption Analysis of Non-Newtonian Fluid}

The relationship between power number $\left(N_{\mathrm{p}}\right)$ and Reynolds number $(R e)$ for a mixing conducted in a vessel with rotational blades is given as below. ${ }^{12,13}$

$$
N_{\mathrm{p}}=\frac{P}{\rho N^{3} d^{5}}
$$

and

$$
R e=\frac{\rho N d^{2}}{\mu_{\mathrm{a}}}
$$


where $P$ is the power $(2 \pi N T, \mathrm{~W}), \rho$ the true density of feedstock $\left(\mathrm{kg} / \mathrm{m}^{3}\right), N$ the blade speed $\left(\mathrm{s}^{-1}\right), d$ the blade diameter $(\mathrm{m})$, and $\mu_{\mathrm{a}}$ the apparent viscosity of non-Newtonian fluid $(\mathrm{Pa} \cdot \mathrm{s})$.

A rheological equation for fluids with a yielding stress, such as in Casson model, is adopted for plastic feedstocks. The shear stress and the apparent viscosity of the feedstock can be correlated according to Casson model. The Casson equation is given as follows:

$$
\tau^{1 / 2}=\tau_{\mathrm{c}}^{1 / 2}+\left(\mu_{\mathrm{c}} \gamma\right)^{1 / 2}
$$

where $\tau$ is the yield strength, $\tau_{\mathrm{c}}$ the Casson yield strength, $\mu_{\mathrm{c}}$ the Casson viscosity, and $\gamma$ the shear rate.

Equation (3) can be transformed into Eq. (4) to get the viscosity $\left(\mu_{\mathrm{a}}\right)$ of a feedstock:

$$
\mu_{\mathrm{a}}^{1 / 2}=\left(\frac{\tau_{\mathrm{c}}}{\gamma}\right)^{1 / 2}+\mu_{\mathrm{c}}^{1 / 2}
$$

\section{Experimental Procedure}

\section{(1) Materials}

The raw materials used in this study include 3Y-TZP (Teamcera, Tauyuan, Taiwan) with a specific BET surface area of $14.0 \mathrm{~m}^{2} / \mathrm{g}$ and 3Y-TZP powder (Tosoh, Tokyo, Japan) of $13.6 \mathrm{~m}^{2} / \mathrm{g}$. The binders for the feedstock include low-density polyethylene (LDPE, USIFE-NA208, Taipei, Taiwan), paraffin wax (PW, Nippon Serio, Tokyo, Japan), and a surfactant with an ester functional group. According to previous result ${ }^{14}$ from the torque rheometer, the solid content of feedstocks was selected to be constant at $54 \mathrm{vol} \%$. The powder without specification for feedstock preparation was the Teamcera TZP powder. The polymeric ingredients were in the following mass ratio: LDPE:PW:surfactant $=25: 70: 5$.

\section{(2) Powder Properties}

The powder properties were obtained from the following four methods.

1. Apparent Density: According to American MPIF-4 standard, ${ }^{15}$ the powder was put into the hopper by Hall flowmeter. Then the powder of a volume of $25 \mathrm{~cm}^{3}$ was packed in the hopper. The apparent density is the value of the mass of powder divided by the volume.

2. Tap Density: The powder was set in a measuring glass cup. Then, up-and-down shaking motion was applied by a cam to reduce the packing height of powder for $60 \mathrm{~min}$. The density was that the mass of the powder divided by the volume after the shaking.

3. Angle of Repose: The powder passed through the Hall flowmeter and dropped freely onto a plate. The angle of repose was a parameter of the interparticle friction. It could be determined from the height and radius of powder pile.

4. Powder Compressing Property: The compressibility measured the ability of a powder batch in a steel die $(1 \mathrm{~mm}$ in diameter) in a loading rate of $1 \mathrm{MPa} / \mathrm{s}$ up to $\sim 145 \mathrm{MPa}$. The density of sample and critical compressing strength were measured after compaction. ${ }^{16}$

\section{(3) Torque Rheometry}

Torque rheometer was self-assembled from a twin-blade kneader with a torque transducer and signal amplifier. ${ }^{5}$ The amplifier transformed the measured torque $(T)$ to an electric signal which could be recorded. The operation controls involved blade speed $(22,30$, or $55 \mathrm{rpm})$ and kneading temperature $\left(130^{\circ}, 150^{\circ}\right.$, or $\left.170^{\circ} \mathrm{C}\right)$. The kneading conditions are shown in Table I.

\section{(4) Optic Microscopy (OM) and Quantitative Analysis of Microstructure}

The feedstock was melted and pressed by glass plates to a thin film with a thickness of about $10 \mu \mathrm{m}$. The feedstock sample was
Table I. TZP Feedstocks Made by Different Kneading Conditions

\begin{tabular}{llccc}
\hline & & \multicolumn{3}{c}{ Kneading conditions } \\
\cline { 3 - 5 } Symbol & 3Y-TZP powder & Temperature $\left({ }^{\circ} \mathrm{C}\right)$ & Blade speed (rpm) & Time (min) \\
\hline A-1 & Teamcera & 130 & 22 & 150 \\
A-2 & & & 30 & \\
A-3 & & 150 & 55 & \\
B-1 & & & 22 & \\
B-2 & & 170 & 30 & \\
B-3 & & & 55 & \\
C-1 & & $170($ I) & 32 & \\
C-2 & & 150 (II) & 30 & 60 \\
C-3 & & 170 (I) & 30 & 90 \\
D & Teamcera & 150 (II) & 30 & 90 \\
& & 170 (I) & 30 & 60 \\
E & Tosoh & 140 (II) & 30 & 90 \\
& & & 30 &
\end{tabular}

TZP, tetragonal zirconia polycrystalline.

inspected using an optic microscope (Nikon HFX-DX, Tokyo, Japan). The color of the powder agglomerate showed black due to the scattering of the transmission light. The resolution of the OM was better than $2 \mu \mathrm{m}$. The dispersive index $\left(D_{\mathrm{s}}\right)$ is defined as a ratio of black area, which shows with at least $10 \mu \mathrm{m}$ in diameter, to total area.

\section{(5) Kneading, Injection-Molding, Debinding, and Sintering}

$\mathrm{ZrO}_{2}$ powder and $\mathrm{PE}$ were first preheated to $130^{\circ}-170^{\circ} \mathrm{C}$ for 60 min in the twin-blade kneader. The wax and surfactant were then added stepwise into the preheated mixture in $12 \mathrm{~min}$. The feedstock was cooled to the temperature and kneaded for additional period according to the conditions specified in Table I. Granulated feedstocks could be obtained as the kneader was cooled to room temperature. An injection-molding machine (CDC900 SM50, CHEN HSONG CO., Chungli, Taiwan) was operated at barrel temperatures set from $145^{\circ}$ to $165^{\circ} \mathrm{C}$ and a hot-sprue temperature set at $140^{\circ}-160^{\circ} \mathrm{C}$. The mold temperature was maintained at $50^{\circ} \mathrm{C}$. The mold was designed to have twin cavities of the test bar in the dimensions of $4.00 \mathrm{~mm} \times 5.15 \mathrm{~mm}$ $\times 49.95 \mathrm{~mm}$. An organic solvent (industrial grade $n$-heptane) was used to extract soluble PW and SA in the IM parts. The solvent debinding was conducted at $50^{\circ} \mathrm{C}$ and held for $2.5 \mathrm{~h}$ in $n$ heptane. More than $80 \mathrm{wt} \%$ of soluble binders could be extracted. After drying, the samples were put to thermal debinding in air furnace according to previous conditions. ${ }^{5}$ Subsequently, the samples were heated at a rate of $10^{\circ}-1480^{\circ} \mathrm{C} / \mathrm{min}$ sintering for $1 \mathrm{~h}$.

\section{(6) Physical Properties of Sintered TZP}

The true density of the sintering body was measured by Archimedes principle. Flexural strength was measured using the bars of $4.0 \mathrm{~mm} \times 3.0 \mathrm{~mm}$ in cross-section in a four-point test, and reported the strength data and standard deviation according to ASTM C1239-95. ${ }^{17}$ The specimens were tested as-fired condition without surface machining.

\section{Results and Discussion}

\section{(1) The Properties of Powder}

Figure 1 shows the granule size distribution of Tosoh and Teamcera spray-drying $3 \mathrm{Y}-\mathrm{TZP}$ powders. The granule size distribution of Tosoh is from 20 to $80 \mu \mathrm{m}$. The shape of the granule powder is nearly dense and spherical. Teamcera powder has a granule size distribution from 80 to $120 \mu \mathrm{m}$ and an apple shape. 


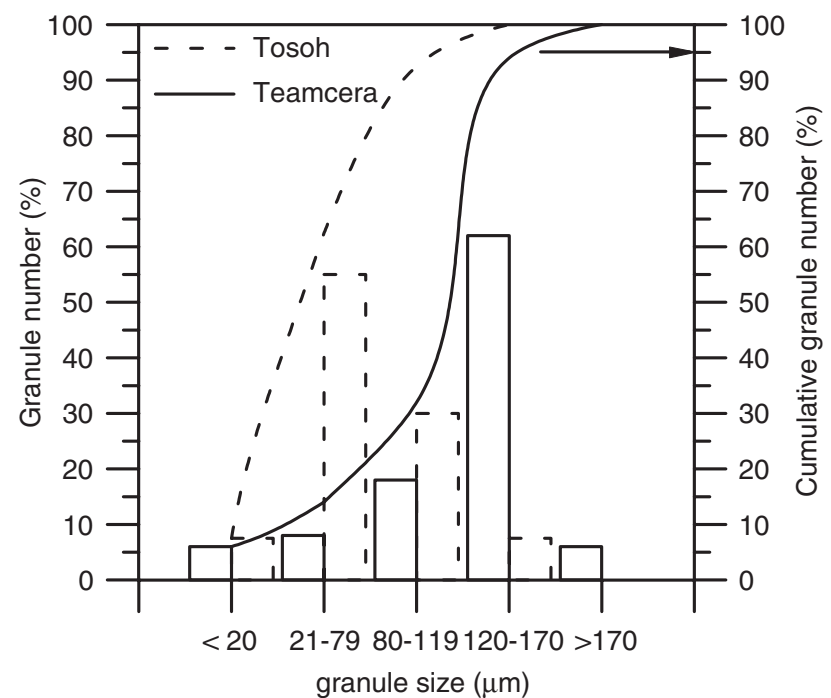

Fig. 1. Granule size distribution of Tosoh and Teamcera powders.

Note that the shape and size distribution of the granules affect the angle of repose and packing density of ceramic feedstock. ${ }^{18}$ The powder properties also affect indirectly the attractive interparticle force and the critical solid content of feedstock.

The relationship between compressing stress and green density of granule powders is shown in Fig. 2. The granule density, granule size distribution, and shape, which characterize the influence of granulation, reveal a powder agglomerate deforming during the compaction process. The critical compressing strength, as the intersect of two fitting lines shown in Fig. 2, of Teamcera powder is $1.8 \mathrm{MPa}$ higher than that of Tosoh powder $(2.8 \mathrm{MPa})$. The agglomerative strength of Teamcera granule powder is lower.

Properties of the powders, such as response angle, flow rate, apparent density, and tapping density are shown in Table II. Tosoh powder has a lower apparent density and a lower tapping density than that of Teamcera powder. This is due to the reasons that Teamcera has a wider distribution in granule size, a greater flow rate, and a higher repose angle than those of the Tosoh. The greater response angle reveals higher inter-particle friction. Besides, the flow rate of Teamcera granule powder is greater than Tosoh. The results predict that the appropriate granule size distribution and shape affect apparent density and tape density

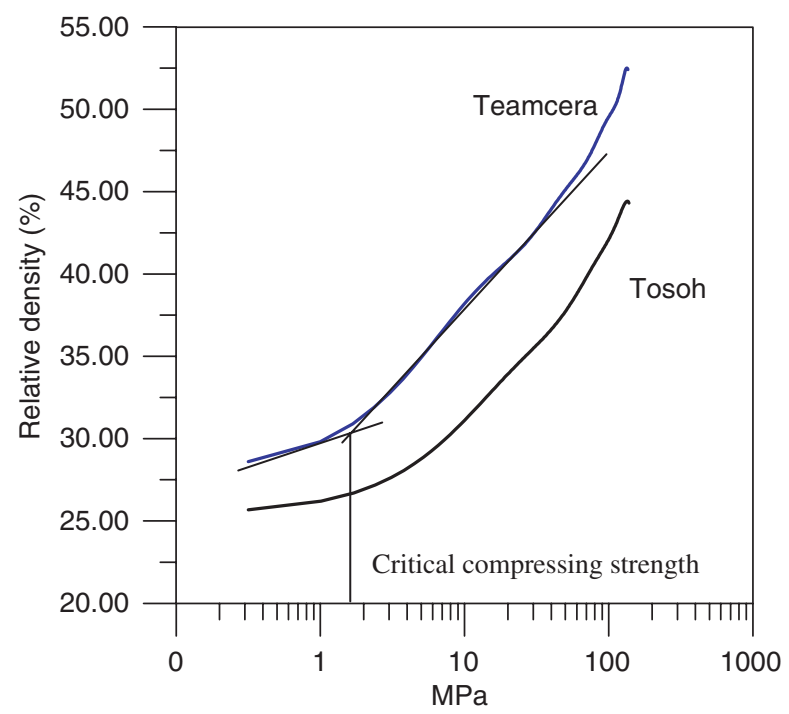

Fig. 2. Compaction diagram of the granules for the cases of Tosoh and Teamcera powders.
Table II. Powder Characteristics of Two TZP Powders

\begin{tabular}{lcc}
\hline & Tosoh & Teamcera \\
\hline Angle of repose (degree) & $31 \pm 1$ & $35 \pm 1$ \\
Flow rate $(\mathrm{g} / \mathrm{s})$ & 0.58 & 1.11 \\
Apparent density $\left(\mathrm{g} / \mathrm{cm}^{3}\right)$ & $1.14 \pm 0.01$ & $1.45 \pm 0.01$ \\
Tap density $\left(\mathrm{g} / \mathrm{cm}^{3}\right)$ & $1.33 \pm 0.01$ & $1.67 \pm 0.01$ \\
Critical average compressing & 2.8 & 1.8 \\
$\quad$ strength $(\mathrm{MPa})$ & & \\
\hline TZP, tetragonal zirconia polycrystalline. & &
\end{tabular}

of granules. In summary, the lower agglomerative strength and higher inter-particle friction of Teamcera granule powder would benefit the performance of kneading process.

\section{(2) Kneading Response of Feedstock}

The kneading response of the zirconia feedstocks fabricated with Teamcera granules was measured by the torque rheometer. Figure 3 shows the torque-temperature-time curve (TTT curve) as a function of the temperature and the kneading speed. The kneading procedure was that zirconia granule powder mixed with polyethylene for $60 \mathrm{~min}$. Then, the surfactant and paraffin wax were added stepwise in $10 \mathrm{~min}$, followed a kneading period for $200 \mathrm{~min}$. Takanhashi et al. ${ }^{19}$ reported four types of kneading torque responses. In this study, most kneading responses are Takanhashi type II, i.e., the torque of feedstock monotonically decreases with increasing kneading time. At the same kneading temperature, the torque at a blade speed $30 \mathrm{rpm}$ is the highest when compared with those at blade speed 55 or $22 \mathrm{rpm}$. The kneading condition of $150^{\circ} \mathrm{C} / 30 \mathrm{rpm}$ results in the highest torque. On the other hand, the kneading response under the other condition is Takanhashi type III, i.e., the torque reduces in $10 \mathrm{~min}$ and increases afterwards with increasing kneading time. One of the special cases is $150^{\circ} \mathrm{C} / 22 \mathrm{rpm}$. This kneading response is not due to the reason ${ }^{19}$ that the solid content of the feedstock is lowest. In our experimental observation, the feed-

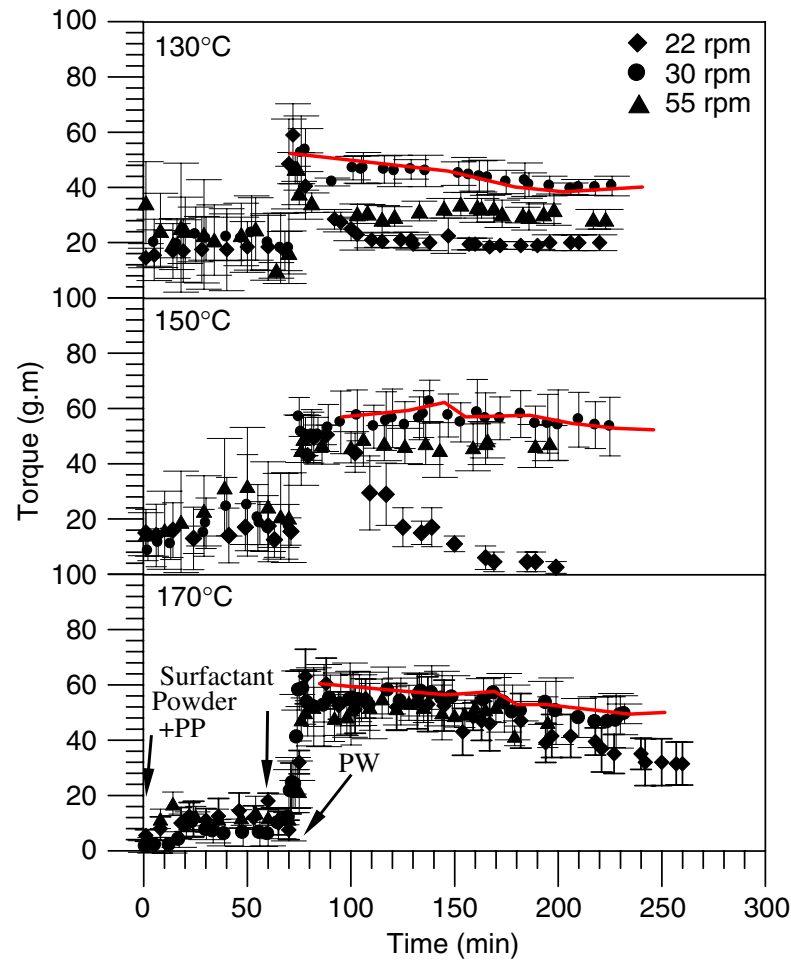

Fig. 3. Torque-time-temperature curves of Yttria-stabilized tetragonal zirconia polycrystallines feedstocks kneading at various temperature and rotation speed conditions. 


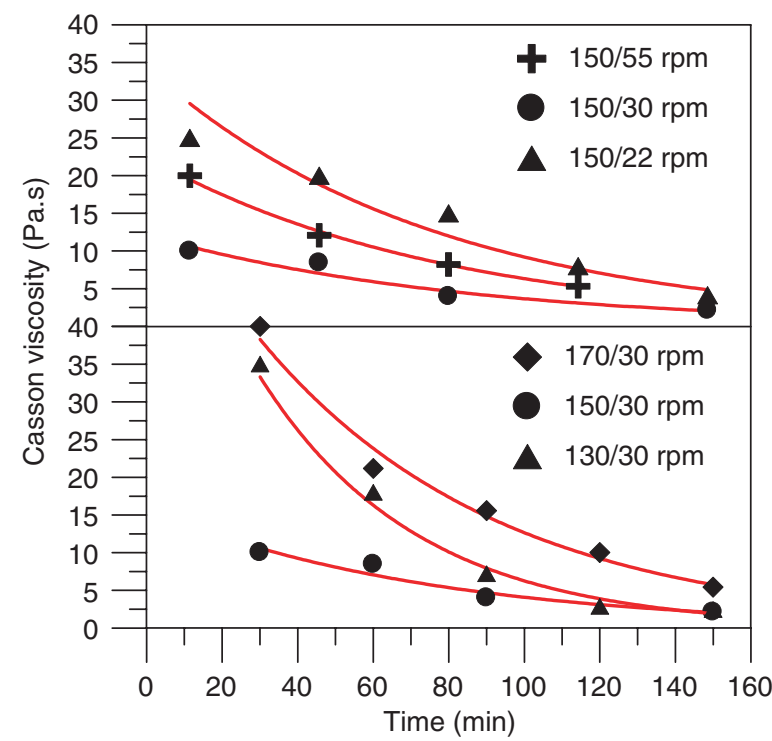

Fig. 4. Casson viscosities of the feedstocks as a function of kneading time by different kneading conditions.

stock in fact adhered to the surface of the two blades and the torque therefore dropped quickly.

The Casson viscosities, which are physically conceived of a viscous flow without considering the yielding at low shear rate of the feedstock, change during the kneading process, as shown in Fig. 4. The Casson viscosities can be calculated by Eq. (4) for the kneading temperatures, respectively, at $130^{\circ}, 150^{\circ}$, and $170^{\circ} \mathrm{C}$. Casson viscosities reduced with increasing kneading time due to powder de-agglomeration in the feedstock. The $170^{\circ} \mathrm{C} / 30 \mathrm{rpm}$ (C-2 condition) resulted in the highest Casson viscosity while the $150^{\circ} \mathrm{C} / 30 \mathrm{rpm}(\mathrm{B}-2$ condition) was the lowest. The difference implies the polymeric carrier shows a highest viscosity at $170^{\circ} \mathrm{C} /$ $30 \mathrm{rpm}$ at kneading stage up to $150 \mathrm{~min}$, and favors the transfer of shear force (or energy) for de-agglomeration more efficient by $170^{\circ} \mathrm{C} / 30 \mathrm{rpm}$.

The Reynolds number, as calculated by Eq. (2), of the feedstocks reveals the variation as a function of the kneading time. As shown in Fig. 5, three different regions can be noted. Those feedstocks kneading at $30 \mathrm{rpm}$ showed lowest Reynolds number while kneading at $130^{\circ} \mathrm{C} / 55 \mathrm{rpm}$ resulted in the highest Reynolds number. However, the Reynolds number remained nearly

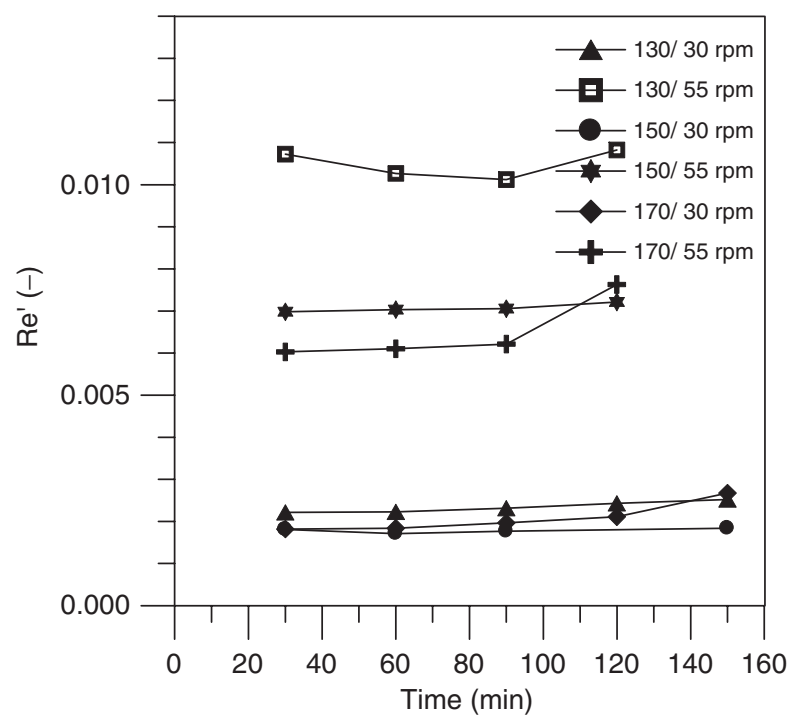

Fig. 5. Reynolds number of the feedstocks plotted against kneading time prepared by different kneading conditions. constant as the kneading time increased. In other words, the Reynolds number was nearly independent of the kneading time.

\section{(3) Evolution of Feedstock Homogeneity}

Figure 6 shows the microstructures of two feedstocks observed by transmission OM. In Fig. 6(a) the black features are the powder agglomerates in the feedstock under $150^{\circ} \mathrm{C} / 30 \mathrm{rpm}(\mathrm{B}-2$ condition) for $5 \mathrm{~min}$. The homogeneity of the B-2 feedstock gradually improves with the kneading time during the next $150 \mathrm{~min}$, as the final case shown in Fig. 6(b). Figures 6(c) and (d) show the thin film micrographs of the feedstock kneaded, respectively, under $130^{\circ} \mathrm{C} / 30 \mathrm{rpm}(\mathrm{A}-2)$ and $170^{\circ} \mathrm{C} / 30 \mathrm{rpm}(\mathrm{C}-2)$ for $150 \mathrm{~min}$. The $\mathrm{B} 2$ feedstock has the best homogeneity among all samples.

Figure 7 shows the statistical agglomerate size distribution in the feedstocks under C-2 condition from 5 to $150 \mathrm{~min}$. The larger powder agglomerates of $30 \mu \mathrm{m}$ were seen at the early stage of kneading. The powder agglomerate number would be reduced gradually after kneading for $60 \mathrm{~min}$. Finally, the agglomerate size of less than $14 \mu \mathrm{m}$ was still held in the feedstock after kneading for $150 \mathrm{~min}$. The viscosity of feedstock was low at kneading temperature of $170^{\circ} \mathrm{C}$. It was difficult to disperse the powder agglomerates completely due to insufficient shear stress transferred by the melted plastic media.

Figure 8 reveals the residual agglomeration $\left(\phi_{\mathrm{a}}\right)$ of the feedstocks as a function of dimensionless kneading time under different kneading conditions. The results showed that kneading at $55 \mathrm{rpm}$ had the modest slope of the kneading curves than the others. Under the same blade speed of $30 \mathrm{rpm}$ the best feedstock de-agglomeration was obtained by kneading at a temperature of $170^{\circ} \mathrm{C}$ for $60 \mathrm{~min}$. After $60 \mathrm{~min}$ the better feedstock homogeneity was achieved by kneading at $150^{\circ} \mathrm{C} / 30 \mathrm{rpm}$ than at $170^{\circ} \mathrm{C} /$ $30 \mathrm{rpm}$. The results revealed that the initial viscosity kneading at $170^{\circ} \mathrm{C}$ was low and this favored distributive and dispersive mixing of the inhomogeneous feedstock. Then, the viscosity of feedstock reduced with increasing kneading time. The shear stress needed to disperse powder agglomerate became insufficient when the feedstock viscosity (the Casson viscosity) continued to decrease after a period of kneading time. The viscosity of the feedstock kneaded at $130^{\circ} \mathrm{C}$ after 60 min was still too high to have distributive mixing. This explains for the better homogeneity of the feedstock at $150^{\circ} \mathrm{C} / 30 \mathrm{rpm}$ after $60 \mathrm{~min}(\mathrm{~B}-2)$.

Figure 9 shows the relationship between the homogeneity of the feedstock and the power number $\left(N_{\mathrm{p}}\right)$. In order to compare the effects of de-agglomeration, the samples were kneaded by consideration of the power input, i.e. $N_{\mathrm{p}}$ value. All samples were kneaded for $150 \mathrm{~min}$. The homogeneity of the feedstock was worse when the $N_{\mathrm{p}}$ (a function of the ratio of $T / N^{2}$ ) was either too large or too small. In other words, the kneading window for the kneader is in the operation of $N_{\mathrm{p}}$ from $3 \times 10^{5}$ to $13 \times 10^{5}$.

The homogeneity of the feedstock was reached with $D_{\mathrm{s}}$ value ranging from 0.40 to $>0.93$ when $N_{\mathrm{p}}$ was produced by a single kneading condition. Two shortcomings were realized. The deagglomeration was only achieved in the $D_{\mathrm{s}}$ level $95 \%$. There were still $5 \%$ agglomerates left in the feedstocks. Second, the kneading operations (A, B, or C in Table I) performed different de-agglomeration capability, as indicated in Fig. 8. The steepest slope of the agglomerate-kneading time curves in different stages of kneading was always desirable because of the need of shorter processing time.

\section{(4) Multiple Kneading Conditions}

The single kneading condition of $150^{\circ} \mathrm{C} / 30 \mathrm{rpm}$ for $150 \mathrm{~min}$ still dispersed powder incompletely $\left(D_{\mathrm{s}}=0.95\right)$. The slope of the kneading curve of $170^{\circ} \mathrm{C} / 30 \mathrm{rpm}$ was the steepest in the first $60 \mathrm{~min}$. The slope for $150^{\circ} \mathrm{C} / 30 \mathrm{rpm}$ was the steepest from 60 to 150 min according to Fig. 8. Therefore, the best kneading procedure was selected to be two-step: $170^{\circ} \mathrm{C} / 30 \mathrm{rpm}$ for $60 \mathrm{~min}$ and followed by $150^{\circ} \mathrm{C} / 30 \mathrm{rpm}$ for $90 \mathrm{~min}$, as the $\mathrm{D}$ and $\mathrm{E}$ conditions shown in Table I. 

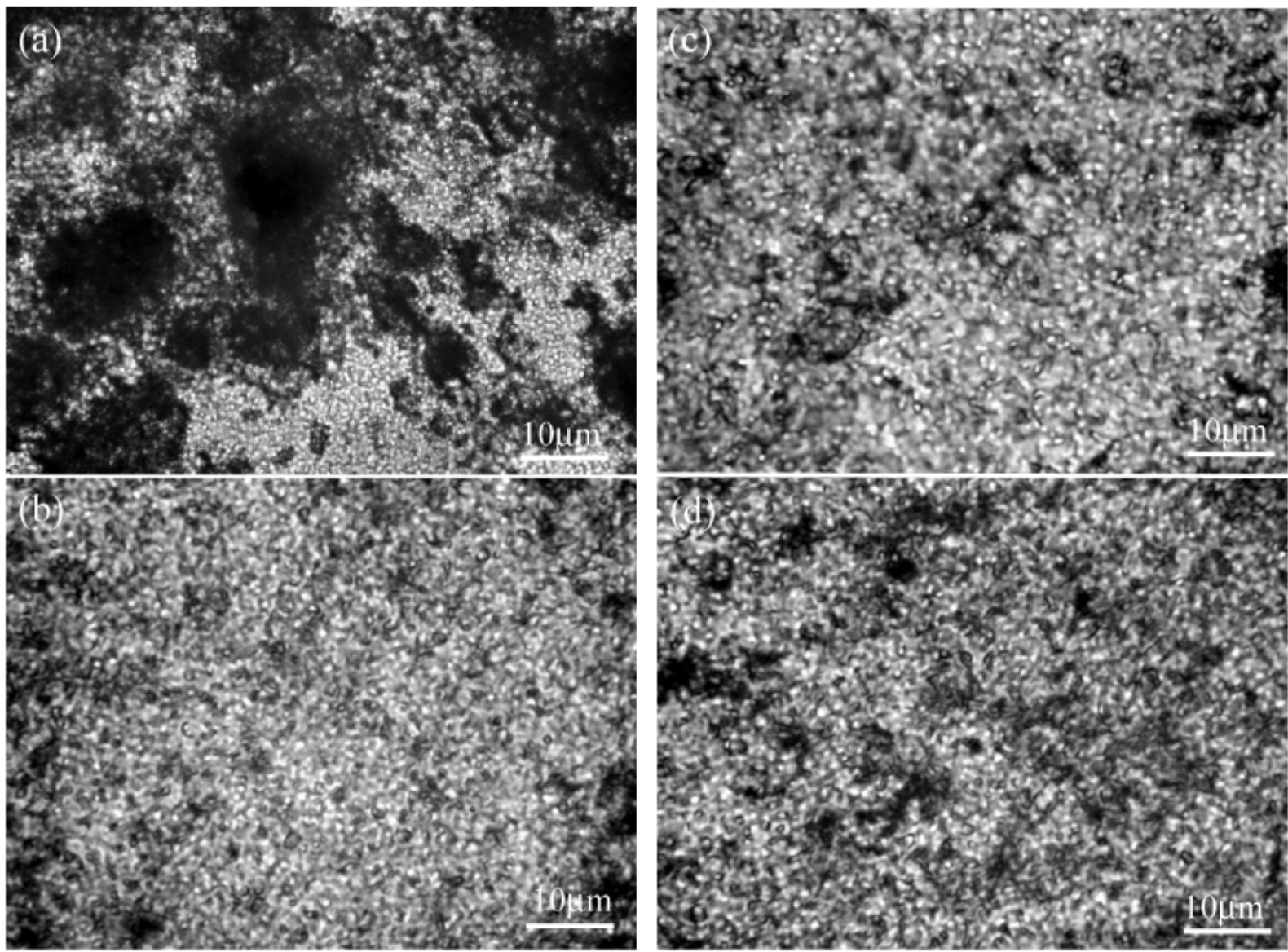

Fig. 6. Thin film morphologies of 3yttria-stabilized tetragonal zirconia polycrystallines feedstock by transmission optic microscopy at $150^{\circ} \mathrm{C} / 30 \mathrm{rpm}$ for (a) 5 and (b) $150 \mathrm{~min}$. (c) $130^{\circ} \mathrm{C} / 30 \mathrm{rpm}$, and (d) $170^{\circ} \mathrm{C} / 30 \mathrm{rpm}$ for $150 \mathrm{~min}$.

The zirconia feedstock with Teamcera granule became highly homogenous $\left(D_{\mathrm{s}}=0.99\right)$ after the two-step kneading procedure stated above (i.e. the D condition in Table I). However, the Tosoh feedstock only attained a homogeneity index, $D_{\mathrm{s}}$ of 0.52 (i.e. the $\mathrm{E}$ condition in Table I). The homogeneity of Tosoh feedstock improved from 0.52 to 0.98 if the second kneading pro-

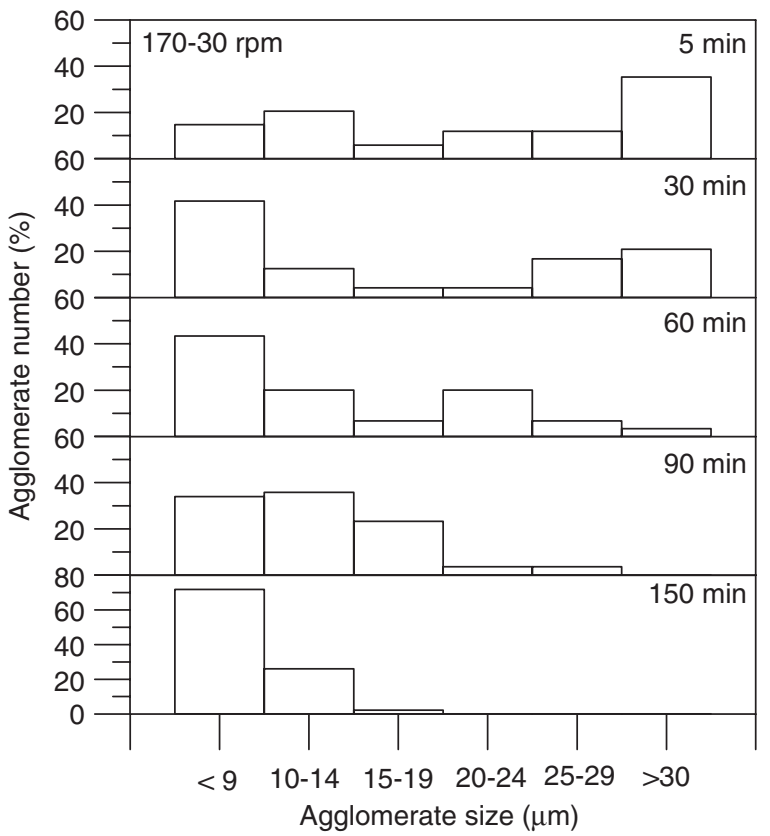

Fig. 7. Relationship between the distribution of agglomerate size and kneading time of the feedstock by $170^{\circ} \mathrm{C} / 30 \mathrm{rpm}$. cedure was changed from $150^{\circ} \mathrm{C} / 30 \mathrm{rpm}$ to $140^{\circ} \mathrm{C} / 30 \mathrm{rpm}$ kneading for $90 \mathrm{~min}$ (i.e. the $\mathrm{E}$ changed to $\mathrm{F}$ condition in Fig. 9 and Table I) due to increasing shear stress of the knead-

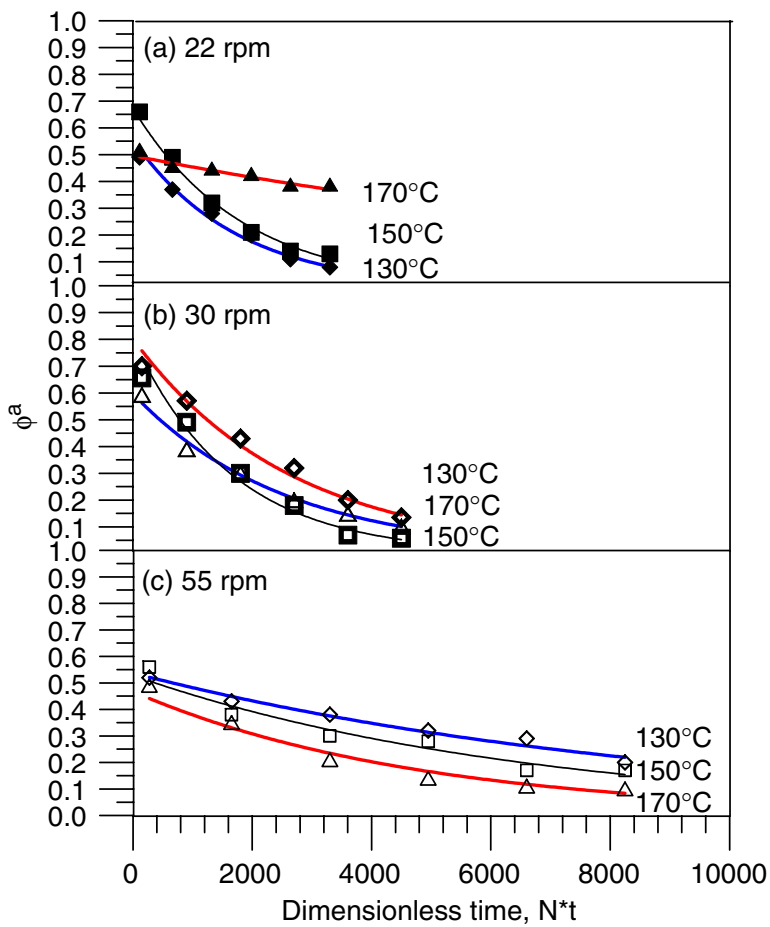

Fig. 8. Fracture of residual agglomeration of the feedstocks as a function of dimensionless time by different kneading conditions. 


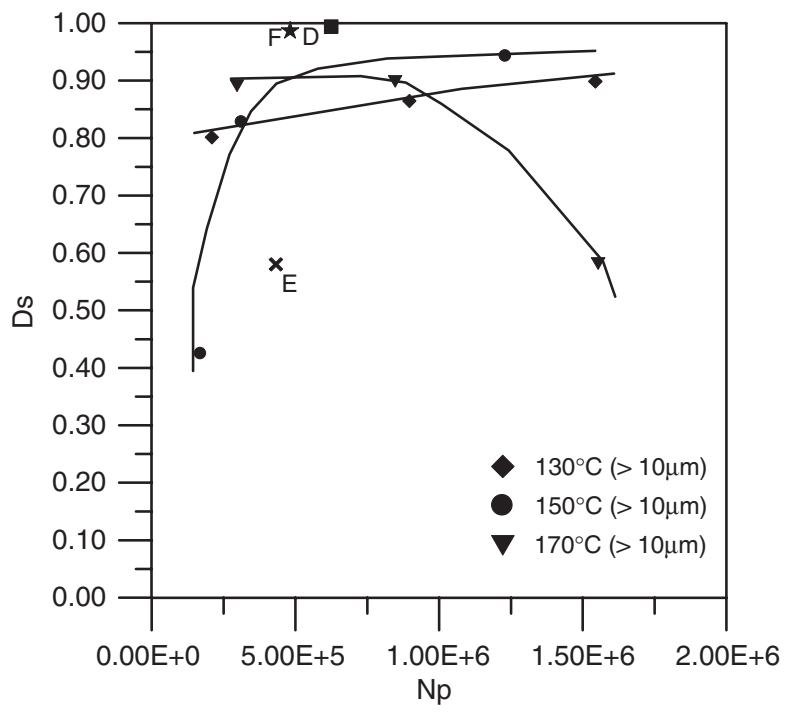

Fig. 9. Dispersive index as a function of power number $\left(N_{\mathrm{p}}\right)$ of the feedstocks kneading at $130^{\circ}, 150^{\circ}$, or $170^{\circ} \mathrm{C}$ for $150 \mathrm{~min}$.

Table III. Dispersive Index of Feedstock, the Average Strength $(\sigma)$, and Standard Deviation (SD) of Made TZP Test Bars

\begin{tabular}{lcccc}
\hline Sample & $D_{\mathrm{s}}$ & $\sigma(\mathrm{MPa})$ & $\mathrm{SD}(\mathrm{MPa})$ & Number of tests \\
\hline $\mathrm{D}$ & 0.99 & 680 & 70 & 30 \\
$\mathrm{~F}$ & 0.98 & 660 & 63 & 30 \\
Previous result $^{10}$ & 0.81 & 520 & 80 & 30 \\
\hline
\end{tabular}

TZP, tetragonal zirconia polycrystalline.

er. The results between kneading behavior and powder properties are consistent. The Teamcera granule powder has a lower critical compressing strength of granule and a higher angle of repose, so the agglomerates can be easily broken down in the kneading process.

The fracture strength of the sintering parts reported in the literature is $735 \pm 80 \mathrm{MPa}^{4}$ or $660 \pm 210 \mathrm{MPa}^{20}$ Two highly homogenous feedstocks (by $\mathrm{F}$ and $\mathrm{D}$ conditions) were fabricated and used for making test bars by injection molding in this study. The relationship between the dispersive index and fracture strength of $3 \mathrm{Y}-\mathrm{TZP}$ sintering parts is shown in Table III. Previous results ${ }^{10}$ that the fracture strength of sintering parts with homogeneity of $D_{\mathrm{s}}=0.81$ was $520 \pm 80 \mathrm{MPa}$. Fracture strengths of the sintering parts are, respectively, $680 \pm 70$ and $660 \pm$ $63 \mathrm{MPa}$ when the homogeneity of feedstock has been improved from $D_{\mathrm{s}}=0.81$ to $D_{\mathrm{s}}=0.98(\mathrm{D})$ and $0.99(\mathrm{~F})$. The fracture strength of the sintering parts (either $\mathrm{D}$ or $\mathrm{F}$ condition) is lower than $735 \pm 80 \mathrm{MPa}$ reported in the literature. ${ }^{4}$ Lower strength is possibly due to a longer kneading time of the $\mathrm{D}$ and $\mathrm{F}$ feedstocks, and partially to the residual granule particles $(1 \%-2 \%)$ in the D and $\mathrm{F}$ samples of this study.

The degradation of the feedstock could occur for a long kneading time, and may lead to a polymer and strength degradations in injection-molded parts. ${ }^{18}$ The prevention of the degradation and the elimination of residual granules can be achieved by using different shear-type kneader and kneading for shorter period. The results will be reported in our next article. ${ }^{21}$

\section{Conclusion}

Shear kneading process is an important technique in CIM to obtain homogeneous feedstocks. The kneading torque and vis- cosity of the feedstocks have been carefully correlated to the de-agglomeration phenomena. TTT curves of the feedstocks revealed at least two types of torque response. Kneading at $150^{\circ} \mathrm{C} /$ $30 \mathrm{rpm}$ resulted in highest torque response. But more precisely, the Casson viscosity measured at $170^{\circ} \mathrm{C} / 30 \mathrm{rpm}$ was the highest, introduced very efficient de-agglomeration process in the initial stage of kneading.

The kneading by controlling temperature and rotation speed does show an operation window. The $N_{\mathrm{p}}$ value for this specific shear kneader should not larger than $13 \times 10^{5}$ or smaller than $3 \times 10^{5}$. Therefore, the torque and viscosity during kneading stage was very effective, and evidenced for shorter evolution of the feedstock de-agglomeration process.

Best kneading procedure was attained in consideration of best homogeneity and shortest kneading time. Homogeneous zirconia feedstocks were kneaded by two-step operation, $170^{\circ} \mathrm{C} / 30$ $\mathrm{rpm}$ for $60 \mathrm{~min}$ and then $150^{\circ} \mathrm{C} / 30 \mathrm{rpm}$ for $90 \mathrm{~min}$. The fracture strength of two sintering parts increased due to better homogeneity of the feedstocks.

\section{References}

${ }^{1}$ J. K. Wright, M. J. Edirisinghe, J. G. Zhang, and J. R. G. Evans, "Particle Packing in Ceramic Injection Molding," J. Am. Ceram. Soc., 73, $2653-8$ (1990).

${ }^{2}$ J. G. Zhang, M. J. Edirisinghe, and J. R. G. Evans, "The Use of Modulated Pressure in Ceramic Injection Moulding," J. Eur. Ceram. Soc., 5, 63-72 (1989).

${ }^{3}$ C.-C. T. Yang, H. J. Cho, and W. J. Wei, "Quantitative Characterization of Various Tetragonal Zirconia Polycrystals (TZPs)," J. Eur. Ceram. Soc., 22, 199-207 (2002).

${ }^{4}$ M. Trunec, P. Dobsak, and J. Cihlar, "Effect of Powder Treatment on Injection Moulded Zirconia Ceramics," J. Eur. Ceram. Soc., 20, 859-66 (2000).

${ }^{5}$ R. Y. Wu and W.-C. J. Wei, "Torque Evolution and Effects on Alumina Feedstocks Prepared by Various Kneading Sequences," J. Eur. Ceram. Soc., 20, 67-75 (2000).

${ }^{6}$ K. N. Hunt, J. R. G. Evans, and J. Woodthrope, "The Influence of Mixing Route on the Properties of Ceramic Injection Moulding Blends," Br. Ceram. Trans. J., 87, 17-21 (1988).

${ }^{7}$ Y. Kawaguchi, M. Kaminoyama, K. Nishi, and M. Kamiwano, "Analysis of Mixing Process for Wet Particle System in a Double Blade Batch Kneader Mixer," J. Chem. Eng. Japan, 30 [3] 550-6 (1997).

${ }^{8}$ J. H. Song and J. R. G. Evans, "The Effect of Undispersed Agglomerates on the Relative Viscosity of Ceramic Moulding Suspensions," J. Mater. Sci. Lett., 13, 1642-4 (1994).

${ }^{9}$ F. F. Lange and M. Metcalf, "Processing-Related Fracture Origins: II, Agglomerate Motion and Cracklike Internal Surface Caused by Differential Sintering," J. Am. Ceram. Soc., 66, 346-98 (1983).

${ }^{10}$ R. Y. Wu and W.-C. J. Wei, "Kneading Behavior and Homogeneity of Zirconia Feedstocks for Micro-Injection Molding," J. Eur. Ceram. Soc., 24, 3653-62 (2004).

${ }^{11}$ Y. Suetsugu, "The Effect of Mixing on Some Properties of Compounds and Composites"; pp. 521-48 in Mixing and Compounding of Polymers: Theory and Practice. Edited by I. Manas-Zloczower and Zehev Tadmor, Hanser Publishers, Munich, 1994.

${ }^{12}$ S. Nagata, Mixing, pp. 66-83. Kodansha Ltd., Tokyo, Japan, 1975.

${ }^{13}$ M. Kamiwano, M. Kaminoyama, K. Nishi, and Y. Suziki, "Power Consumption Diagram for Wet Particle Kneader Mixers - In the Case That Rheological Properties for Wet Particles Cannot be Measured," J. Chem. Eng. Japan, 33 [3] 489-98 (2000).

${ }^{14}$ R. Y. Wu and W.-C. J. Wei, "Effects of Surfactant on Mg-PSZ Feedstocks for Powder Injection Molding"; The Fifth IUMRD International Conference on Advanced Materials, IUMRS-ICAM' 99, China, 2000.

15"'Standard Test Methods for Metal Powders and Powder Metallurgy Products," MPIF standard. MPIF Princeton, NJ, U.S.A., 2003.

${ }^{16}$ J. H. Song and J. R. G. Evans, "A Die Pressing Test for the Estimation of Agglomerate Strength,” J. Am. Ceram. Soc., 77 [3] 806-14 (1994).

${ }_{17}$ "Standard Practice for Reporting Uniaxial Strength Data and Estimating Weibull Distribution Parameters for Advanced Ceramics"; ASTM C1239-95.

${ }^{18}$ R. M. German and A. Bose, Injection Molding of Metals and Ceramics. Powder Industries Federation, Princeton, NJ, 1997.

${ }^{19}$ M. Takahashi, S. Suzuki, H. Nitanda, and E. Arai, "Mixing and Flow Characteristics in the Alumina/Thermoplastic Resin System," J. Am. Ceram. Soc., 71 [12] 1093-9 (1988)

${ }^{20}$ J. H. Song and J. R. G. Evans, "The Assessment of Dispersion of Fine Ceramic Powders for Injection Moulding and Related Processes," J. Eur. Ceram. Soc., 12, 467-78 (1993).

${ }^{21}$ R. Y. Wu and W. J. Wei, "Study on the Preparation of Homogeneous Zirconia Feedstocks Prepared by Various Kneading Mechanisms," J. Mat. Sci. Eng., 36 [4] 236-47 (2004). 